МАКАРЕНКО Екатерина Игоревна - кандидат исторических наук, доцент кафедры социологии и управления Московского автомобильно-дорожного государственного технического университета (МАДИ) (125319, Россия, г. Москва, Ленинградский пр-кт, 64; Makarenko_madi@mail.ru)

\title{
СУБЪЕКТНОСТЬ ОТЕЧЕСТВЕННОЙ ТЕХНИЧЕСКОЙ ИНТЕЛЛИГЕНЦИИ В ОСУЩЕСТВЛЕНИИ ЗАДАЧ ИНФОРМАТИЗАЦИИ
}

Аннотация. В статье рассматриваются проблемы решения неотложных задач, стоящих перед российским обществом, с методологической позиции субъектности отечественной технической интеллигенции. На основе эмпирических данных, полученных автором в результате опроса экспертного сообщества технической интеллигенции (апрель 2019 г.), показаны основные приоритеты инновационного развития, в т.ч. информатизация, проблемы, с которыми сталкиваются представители технической интеллигенции в своей деятельности, а также меры, необходимые для создания современной информационной инновационной среды.

Ключевые слова: субъект, субъектность, актор, информатизация, техническая интеллигенция, инновационная деятельность

Б ольшой интерес вызывает актуальная рубрика об информатизации современной жизни, которая была предложена редакцией журнала [Лапшин 2019]. Действительно, в настоящее время изучение любого социального явления или процесса без учета влияния информатизации и цифровизации становится неполным и неглубоким. В этом плане опубликованная на страницах этого журнала статья известного философа и социолога О.Н. Яницкого о важнейших проблемах перехода к информационному обществу заставляет задуматься о сложностях их реализации в российском обществе. В работе ученый сформулировал 4 неотложные задачи, от решения которых зависит дальнейшее развитие российского общества:

- уменьшение зависимости экономики, политики и жизни всего населения от нефтегазового сектора;

- восстановление промышленного потенциала страны, во многом утраченного за годы перестройки;

- собственно переход к производству и социальному воспроизводству страны, основанный на принципах и институциях информационного общества;

- осуществление названных выше мер в условиях гибридной войны, которая ведется против нас консолидированным Западом экономическими, политическими и медиасредствами [Яницкий 2019].

Такая постановка задач требует их осмысления с точки зрения поиска акторов, активных субъектов преобразований, способных эффективно действовать в этом ключе, а также сложностей, препятствующих их реализации. В данном случае воспользуемся методологическим инструментарием субъектности определенных социальных групп и страт. Академик М.К. Горшков выделил «черты субъектности» современного общества по отношению к гражданскому активизму: «основными его носителями являются люди с активной позицией в отношении собственного бытия и будущего, имеющие амбиции в различных сферах жизнедеятельности (особенно в образовании, самореализации (социальных коммуникациях), ориентированные на нонконформизм, инициативность и предприимчивость, готовые к борьбе за свои права и позитивные перемены в среде обитания» [Горшков 2016]. 
В этом ключе к проблемам осмысления субъектности подходят и другие ученые. А.И. Пальцев рассматривает субъектность с политической точки зрения и соотносит ее с субъектностью нации - «как способность осознавать, ставить и реализовывать собственные цели, являющиеся имманентными ее национальным интересам, и государственной безопасностью, представляющей состояние системы государственного устройства, отвечающее требованиям надежного, эффективного и безопасного функционирования, обеспечивающего жизнедеятельность, развитие и защиту нации» [Пальцев 2019]. С социально-экономической точки зрения субъект рассматривается в качестве субъекта производственных отношений и активного участника производства А.С. Лившицом, Р.С. Ибрагимовой, В.А. Новиковым, В.И. Куликовым [Лившиц и др. 2017: 35]. Вопросы субъектности, обращенные непосредственно к интеллигенции, поднимались в работе Г.И. Козырева [Козырев 2019]. В рамках субъектно-деятельностного подхода, предложенного Ю.Г. Волковым, можно проследить реализацию отечественной технической интеллигенцией ее действий на практике, опираясь на эмпирические факты: «при реализации субъектно-деятельностного подхода нужно выделить принципы дифференциации, акценты на прошлом, настоящем и будущем, потому что речь идет о временной ориентации общества, а также рассматривать в качестве основных временных исследовательских параметров потенциал будущего определенных социальных групп и слоев, связанных с возможностями социальной капитализации, субъективными временными ориентациями, социальными ожиданиями и возможностями реализации перемен» [Волков 2017].

В деятельностном понимании обращались к проблемам субъекта и субъектности и зарубежные ученые. Так, Т. Парсонс, разрабатывая структуру социального действия, выделял «деятеля», «агента», «актора» как субъектов социального действия и первоочередной компонент в самой структуре действия [Парсонс 2018: 72-73]. Деятельностного, активистского подхода к субъекту придерживался и А. Турен, подразумевая под субъектом личностное и индивидуальное начало. «Сущность субъекта заключена в стремлении индивидуума быть действующим лицом, а субъективизация есть не что иное, как желание индивидуализации; данный процесс может развиваться только в том случае, если имеет место достаточный контакт между миром инструментальности и миром идентичности... Моим центральным тезисом является связь идеи субъекта с идеей социальной активности... Субъект - это не рефлексия индивидуума по собственному поводу, не идеальный образ, рисуемый им в гордом одиночестве, а непосредственное действие» [Турен 1999: 488]. П. Штомпка указывает на идеальную комбинацию, которая создается благодаря творческой деятельности субъекта и связанных с ним богатых и гибких социальных структур, благоприятных и активно воспринимаемых им естественных условий, традиций. Также в эту комбинацию входит оптимистичный, долгосрочный взгляд субъекта на будущее и его планирование. Принципиально важен вывод, к которому приходит ученый: «реализация потенциальных возможностей субъекта деятельности посредством практики способствует их расширению, а его эмансипация через действие во времени увеличивает его свободу и усиливает тенденцию к “самотрансцентдентности”. Тенденция к самотрансцендентности происходит в т.ч. из склонности к инновациям, выдвижению новых идей» [Штомпка 1996: 64]. В конечном итоге, можно считать, что субъектность - это возможность самореализации в социуме как на уровне индивидов, так и на уровне отельных социальных групп и страт.

Полагаю, что в плане поиска групп, или слоев с социологической точки зрения такой стратой (субъектом), способной к решению задач информатизации, 
может стать современная техническая интеллигенция. Чем это обусловлено? Во-первых, техническая интеллигенция как социальный слой специалистов с высшим техническим образованием, занятых в производстве, а также в сфере разработки интеллектуального продукта для развития науки и техники, обладает значительными интеллектуальными и профессиональными ресурсами и потенциалом, которые она может реализовать в своей деятельности. Во-вторых, занятость в промышленном производстве предоставляет ей возможность мобильно реагировать на новые технологические изменения, в т.ч. на информатизацию.

В январе-апреле 2019 г. автор методом экспертного опроса провел социологическое исследование «Инновационная деятельность технической интеллигенции». Были опрошены 51 эксперт (муж. - 36, жен. - 15; докторов наук -8 , кандидатов наук - 16), занятые в сферах промышленного производства, услуг, оборонно-промышленного комплекса, научного обеспечения производственной деятельности. Учитывая методические правила, необходимые для экспертного опроса, многие вопросы носили открытый характер. Респонденты активно отвечали на них, ответы носили развернутый характер. По окончании полевого этапа опроса из 51 анкеты только в 6 респонденты не высказали свое дополнительное мнение по различным проблемам, указанным в анкете.

Одним из основных параметров реализации своей субъектности технической интеллигенцией в инновационной деятельности является ее включенность в процесс информатизации, его понимание и оценка. Данные опроса свидетельствуют, что техническая интеллигенция придает особо важное значение «развитию и распространению информационных технологий». По итогам линейного распределения позиций вопроса: «Какие направления научно-технической и промышленной политики представляют особо важное значение для инновационных преобразований в российском обществе?»- указанное выше направление заняло 2-е место - 38,8\%. (Необходимо отметить, что было предложено 10 позиций и можно было отметить несколько вариантов ответа.) 1-е место респонденты отдали «стимулированию инноваций, внедрению изобретений и новых технологий» - 60\%. Наименьшее значение в вопросе важности приоритетов научно-технического и промышленного развития респонденты придают «созданию государственных фондов развития промышленности» $(9,2 \%)$, а также «созданию венчурных фондов для поддержки стартапов - также 9,2\%. Промежуточные значения заняли такие ответы, как «развитие системы технического образования» - 31,4\%; «поддержка оборонных предприятий, создание новых видов вооружения» - 22,2\%; «повышение эффективности уже работающих производств» - 22,2\%; «повышение эффективности управления» - 20,3\%; «повышение энергоэффективности» - 14,8\%; «разработка космических технологий и коммуникаций» - 20,3\%. Как видим, у экспертного сообщества технической интеллигенции присутствует четкое понимание важности информатизации и ее влияния на инновационное развитие. Более того, мнение экспертов по этому вопросу совпадает с выделением именно цифровых инноваций как наиболее соответствующих современному типу производства.

Оценка необходимых навыков и компетенций работников, по мнению представителей технической интеллигенции, также лежит в плоскости «владения информационными технологиями» - 54,1\% (можно было указать несколько позиций). Уступают этой позиции «обладание фундаментальными техническим знаниями» - 48,1\%; «владение иностранными языками» $-31,4 \%$; «умение организовать свой труд» - 31,4\%; «способность быстро адаптироваться к новым экономическим условиям» - 14,8\%; «готовность к смене профессии» - 12,9\%; «владение нормами корпоративной культуры» - 11,1\%. Для соответствия современным требованиям производства в наибольшей степени необходимо, 
по мнению экспертов, «постоянно повышать свою квалификацию» $(64,8 \%)$. Безусловно, это объясняется постоянным и быстрым изменением технологий, в т.ч. информационных. Мы понимаем это как гипотетически ожидаемые данные, справедливо отмеченные респондентами, поскольку цифровизация в мире во многих сферах производства и промышленности не просто набирает обороты, но и становится определяющим технологическим трендом (можно сказать, что «маховик цифры» вращается все сильнее в развитых странах, а в некоторых сферах промышленности - и в нашей стране, например в ОПК). И экспертное сообщество подтверждает этот факт.

Однако в повсеместном широком распространении информатизации и цифровых технологий есть существенные препоны, которые не позволяют современной отечественной технической интеллигенции как стать полноценным субъектом (актором) внедрения инноваций, так и эффективно решать указанные выше задачи, стоящие перед российским обществом в связи с глобальной цифровизацией.

Что препятствует, по мнению экспертов, решению задач инновационного развития и распространению цифровых технологий? В рамках указанного опроса респондентами были предоставлены 34 ответа на открытый вопрос: «Как Вы считаете, почему в промышленной сфере российского общества в настоящее время не внедряются в достаточной степени инновации?» Автор провел кодификацию ответов и выделил основные причины недостаточного внедрения инноваций в промышленность. На управленческом уровне к ним можно отнести: «отсутствие гибкости руководства предприятий, неэффективное и неправильное расставление приоритетов, экономия на ремонте и усовершенствовании существующей приборной базы» (муж., 31-40 лет, научно-исследовательская сфера); «отсутствие строгого контроля за реализацией планов внедрения инноваций» (муж., 41-50 лет, сфера услуг); «неготовность к длинным инновациям» (муж., 41-50 лет, промышленный сектор); «консерватизм руководящего состава» (жен., 31-40 лет, ОПК).

Многие респонденты указывали на финансово-экономические трудности: «необходимы экономические механизмы, способствующие внедрению инноваций» (муж., 31-40 лет, промышленный сектор); «нехватка экономических ресурсов» (жен., до 30 лет, научно-исследовательский сектор); «низкий уровень развития финансовой системы (банкротство банков)» (жен., свыше 60 лет, ОПК); «отсутствие у предприятий ресурсов, необходимых для внедрения инноваций, отсутствие в структуре цены продукции, затраченной на НИР и кадровое обеспечение» (муж., 41-50 лет, сфера услуг); «высокая стоимость их внедрения, не учитывается применение инноваций в расценках» (муж., 41-50 лет, научноисследовательский сектор); «нет экономических стимулов, инвестиций» (муж., 41-50 лет, промышленный сектор экономики); «низкая конкуренция (или ее отсутствие)» (муж., 31-40 лет, промышленный сектор).

Выделили эксперты и такие сложности, как незаинтересованность как государственных бюрократических структур, так и ряда собственников в обеспечении инноваций: «отсутствие заинтересованности у тех, от кого это зависит» (жен., свыше 60 лет, ОПК); «отсутствие желания и финансирования» (жен., 51-60 лет, ОПК); «отсутствие реально заинтересованных лиц» (муж., 41-50 лет, сфера услуг); «страх изменений» (жен., 31-40 лет, научно-исследовательский сектор). Один из респондентов так отметил суть незаинтересованности: «собственность недр страны» (муж., 31-40 лет, промышленный сектор), полагая, что именно богатые природные ресурсы сдерживают развитие инноваций.

В рамках опроса было предоставлено и такое понимание сложностей, связанное с образованием и наукой: «низкий уровень технической культуры обще- 
ства» (муж., 51-60 лет, промышленный сектор экономики); «недостаток квалифицированных работников, административные барьеры и коррупция (жен., до 30 лет, промышленный сектор экономики); «малое число специалистов, научных центров, нехватка современного инструментария для специалистов» (до 30 лет, научно-исследовательский сектор и ОПК (респондент отметил 2 позиции). Как видим, основные препятствия связаны, по мнению экспертов, с управленческим звеном в решении задач информатизации.

В этом плане обратимся к пониманию мер, необходимых для преодоления сложностей инновационного процесса и его препятствий. Эксперты дали 27 ответов на открытый вопрос об их представлениях о необходимых мерах для развития инновационной инфраструктуры. Полученные ответы кодифицированы по 5 наиболее общим параметрам и представлены в иерархическом порядке по числу указанных позиций.

1. Изменение управленческих стратегий, в т.ч. «разъяснение необходимости проведения инноваций, четкая и грамотная программа внедрения инноваций» (муж., промышленный сектор экономики, руководитель отдела); «поставить к управлению профессионалов, но где их взять» (жен., сфера услуг, ИТР); «создание процедуры внедрения инноваций и информатизации (гибкий коридор)» (муж., ОПК, руководитель предприятия).

2. Развитие институтов образования. Здесь необходимо отметить, что в ответах респондентов в разной форме содержалось требование повышения качества общего, и прежде всего технического, образования.

3-4. Эти места разделили такие общие параметры, как «изменение научнотехнической и инновационной политики на государственном уровне» и «финансирование инноваций». В частности, эксперты указали, что необходимо «изменить политику государства, обычными призывами проблему не решить» (муж., научно-исследовательский сектор, д.тех.н., руководитель отела или предприятия); «изменить политический курс на развитие страны, на развитие образования и промышленности» (муж., промышленный сектор экономики, ИТР); «выполнение указов президента в полном объеме (господдержка)» (муж., сектор услуг, ИТР); «увеличение средств именно на инновации и информатизацию» (жен., сфера услуг, ИТР).

5. Научно-исследовательская деятельность. Многие эксперты высказались за «объединение научных подразделений институтов, кафедр с промышленными предприятиями» и «повышение уровня научных разработок».

Анализ двух показателей показывает, что изменение управленческих стратегий является одной из самых важных проблем в решении вопросов перехода страны на инновационный уровень и проблем информатизации. Участники инновационного процесса, занятые в различных сферах и заинтересованные в реальном внедрении новых технологий, в т.ч. информационных, придают большое значение управленческим изменениям как на уровне организации, так и на уровне государства и отрасли. Стоит отметить тот факт, что приоритеты управления поставлены экспертами выше, чем финансирование и материальное обеспечение инновационной инфраструктуры. Здесь можно увидеть ключ к решению задач, стоящих перед российским обществом в плане информатизации: проблема не в деньгах, а в необходимом их приложении и управленческом обеспечении.

Рассуждая о субъектности российской технической интеллигенции, нельзя обойти такой ее сущностный аспект, как особая нравственная позиция, гуманизм, широта кругозора и мировоззрения, патриотический настрой. Именно с этих морально-нравственных характеристик начала формироваться данная социальная страта в конце XIX - начале XX в. Социальная ответственность, 
желание проявить себя в науке, совершить научные открытия не только для себя, но и для общества в целом характеризовали и советскую научно-техническую интеллигенцию в середине XX в. Для полноценной реализации задач, стоящих перед российским обществом в настоящее время, в т.ч. задачи информатизации, необходимо продолжение преемственности отечественной технической интеллигенции в вопросах морально-нравственных императивов, которая, к сожалению, утрачивается [Макаренко 2018]. Этот фактор снижает ее субъектность, активность, мотивацию деятельности. Особая роль технической интеллигенции, связанная с мощными интеллектуальными и профессиональными ресурсами в решении задач создания инновационной структуры, должна бы помочь взглянуть на проблемы информатизации с позиции социальной ответственности, широкого понимания информатизации не только как технологически определенных инновационных действий, но и как развития гуманитарных настроений в обществе, способствующих преодолению террористических угроз. Более того, в условиях современной глобализации эти проблемы выходят на первый план и в международном контексте. На состоявшемся в 2019 г. Всемирном экономическом форуме в Давосе, которой проходил под девизом «Глобализация 4.0: создание глобальной архитектуры в эпоху четвертой индустриальной революции», главной темой обсуждения стали последствия глобализации и индустриальной дигитализации. Одной их характерных особенностей проявления процессов современной глобализации стала нестабильность мирового порядка, отсутствие учета мнения многих групп и слоев общества, недоверие к элитам населения многих стран. И в этом контексте возврат к тенденции гуманитаризации и нравственных императивов осуществления информатизации становится объективной реальностью. «Глобализация 4.0» должна учитывать интересы всех членов общества, в большей степени базируясь на принципах морали. «Нам нужна реморализация глобализации», - заключает исполнительный председатель форума К. Шваб ${ }^{1}$. Без этого невозможно дальнейшее продвижение цифровой революции в мире и решение задач, стоящих перед российским обществом.

Итак, можно заключить, что субъектность российской технической интеллигенции понимается как реализация своих возможностей, потребностей, активности, мотивация деятельности. В этом плане техническая интеллигенция имеет в российском обществе значительные возможности для реализации. Однако ее субъектность сковывается неразвитостью инновационной и информационной инфраструктуры, которая прежде всего лежит в плоскости изменения управления в сфере инноваций и информатизации.

Обращение к моральным императивам, являющимся имманентными качествами многих поколений отечественной технической интеллигенции, имеет актуальный характер. Без понимания гуманитарной и социальной сущности современных инновационных трендов невозможно развитие инноваций и решение задач информатизации.

\section{Список литературы}

Волков Ю.Г. 2017. Социология будущего: социологическое знание и социальный проект: монография. М.: КНОРУС. 176 с.

Горшков М.К. 2016. Российский социум в условиях кризисного развития: контекстный подход. - Социс. Социологические исследования. № 12. С. 26-35.

Козырев Г.И. 2019. Субъектность русской интеллигенции в защите рус-

\footnotetext{
1 Беккер А., Дельфинов А. Глобализация 4.0, или проблемы форума в Давосе. Доступ: https://www. dw.com/ru/глобализация-40-или-проблемы-форума-в-давосе/а-47150519 (проверено 24.05.2020).
} 
ского мира. - Судьбы российской интеллигенции: прошлое, настоящее, будущее. Материалы XX Международной теоретико-методологической конференции: сборник статей (под общ. ред. Ж.Т. Тощенко). М.: Изд-во РГГУ. С. 257-264.

Лапшин А.О. 2019. Глобализация и цифровое общество: заметки на полях. Власть. Т. 27. № 1. С. 63-68.

Лившиц А.С., Ибрагимова Р.С., Новиков В.А., Куликов В.И. 2017. Промышленная политика и антикризисное управление предприятиями: монография. М.: РИОР; ИНФРА-М. 246 с.

Макаренко Е.И. 2018. Социально-исторические особенности воспроизводства технической интеллигенции. - Власть. Т. 26. № 7. С. 197-204.

Пальцев А.И. 2019. Субъектность нации и государственная безопасность России. - Власть. Т. 27. № 2. С. 133-136.

Парсонс Т. 2018. О структуре социального действия (пер. с англ.). М.: Академический проект. 435 с.

Турен А. 1999. Способны ли мы жить вместе? Разные и различные. - Новая постиндустриальная волна на Западе: антология (под ред. В.Л. Иноземцева). M.: Academia.

Штомпка П. 1996. Социология социальных изменений (пер. с англ.; под ред. В.А. Ядова). М.: Аспект-Пресс. 416 с.

Яницкий О.Н. 2019. Переход на «цифру» и задачи науки и образования. Власть. Т. 27. № 1. С. 69-75.

MAKARENKO Ekaterina Igorevna, Cand.Sci. (Hist.), Associate Professor of the Chair of Sociology and Management, Moscow Automobile and Road Construction State Technical University (MADI) (64 Leningradsky Ave, Moscow, Russia, 125319; Makarenko_madi@mail.ru)

\section{SUBJECTIVITY OF THE RUSSIAN TECHNICAL INTELLIGENTSIA IN THE IMPLEMENTATION OF COMPUTERIZATION TASKS}

\footnotetext{
Abstract. The article deals with the problems of solving urgent problems facing the Russian society from the methodological position of subjectivity of the Russian technical intelligentsia. Based on empirical data obtained by the author as a result of a survey of the expert community of technical intelligentsia (April 2019), the author shows the main priorities of innovative development, including informatization, problems faced by representatives of the technical intelligentsia in their activities, as well as measures necessary to create a modern information and innovation environment.

Keywords: subject, subjectivity, actor, informatization, technical intelligentsia, innovative activity
} 